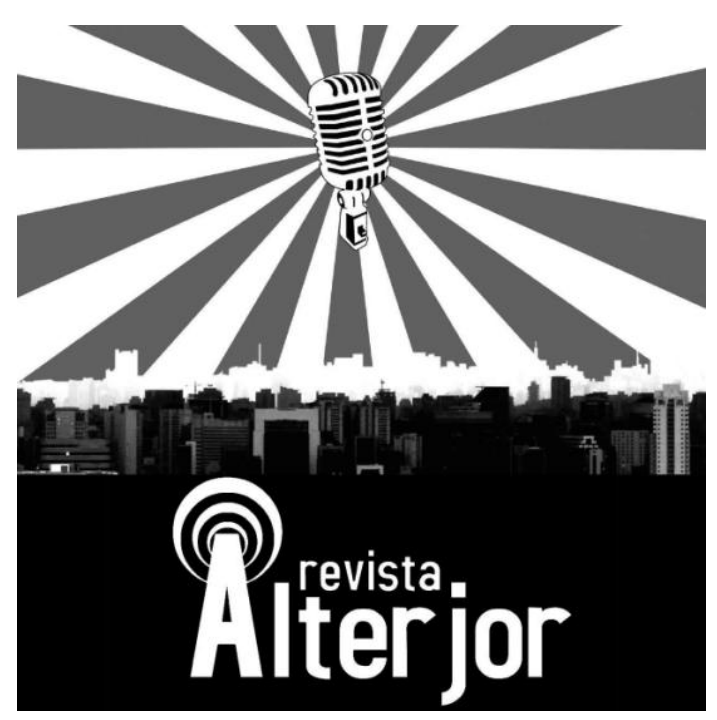

ENTREVISTA

\title{
SÉRGIO SETTANI GIGLIO - \\ A COBERTURA MIDIÁTICA POLIESPORTIVA E REÇÃO ENTRE OS JOGOS ABERTOS DO INTERIOR E OS JOGOS OLÍMPICOS
}

\author{
Gustavo de Araujo Longo ${ }^{1}$
}

\begin{abstract}
RESUMO: Professor de graduação e pós-graduação da Universidade Estadual de Campinas (UNICAMP), Sérgio Settani Giglio é uma das referências sobre estudos interdisciplinares envolvendo o Futebol e os Jogos Olímpicos. Mestre pela UNICAMP e Doutor em Educação Física pela Universidade de São Paulo (USP), é autor de livros e artigos sobre os temas como Futebol, Copa do Mundo, Jogos Olímpicos, Esporte e Política e Ensino dos Esportes Coletivos. Nesta entrevista, ele analisa a cobertura midiática dos Jogos Abertos do Interior, principal evento esportivo do estado de São Paulo, e a relação que possui com os Jogos Olímpicos.
\end{abstract}

PALAVRAS-CHAVE: Jornalismo Esportivo. Jogos Olímpicos. Jogos Abertos do Interior. Sérgio Settani Giglio.

ABSTRACT: Graduation and Post-Graduation professor at the State University of Campinas (UNICAMP), Sérgio Settani Giglio is one of the references on interdisciplinary studies involving Football and the Olympic Games. Master by UNICAMP and Doctor by the University of São Paulo (USP) in Physical Education, in his career he has written or organized books and papers on topics such as Football, World Cup, Olympic Games, Sports and Politics and Teaching Collective sports. In this interview, he makes his analysis and presents considerations involving the media coverage of the Open Games of the Interior, the main sporting event in the state of São Paulo, and its relationship with the Olympic Games.

KEYWORDS: Sports Journalism. Olympic Games. Interior Open Games. Sérgio Settani Giglio.

\footnotetext{
${ }^{1}$ Mestrando pelo Programa de Pós-Graduação em Ciências da Comunicação da Escola de Comunicação e Artes da Universidade de São Paulo (PPGCOM ECA-USP). São Paulo | SP | Brasil. ORCID: 0000-00018798-0790. Bolsista CAPES. E-mail: gu.longo@usp.br.
}

Revista ALTERJOR

Grupo de Estudos Alterjor:Jornalismo Popular e Alternativo (ECA-USP)

Ano 10 Volume 02 Edição 22 Juho-Dezembro de 2020

Avenida Professor Lúcio Martins Rodriģues, 443, Cidade Universitária, São Paulo, CEP: 05508-020 


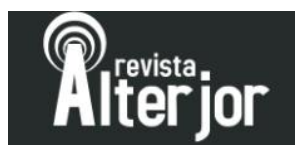

\section{Introdução}

Aos 17 anos, no momento de escolher qual carreira iria prestar no vestibular, Sérgio Settani Giglio tinha duas opções em mente: jornalismo ou educação física, influência direta de sua paixão pelo futebol. Acabou escolhendo a educação física. Passou no processo seletivo da Universidade Estadual de Campinas (UNICAMP) em 1999 e, desde então, construiu sólida carreira acadêmica na área, com Mestrado na UNICAMP, desenvolvendo a dissertação "Futebol: mitos, ídolos e heróis" em 2007, e Doutorado na Universidade de São Paulo (USP) em 2013 com a tese "COI x FIFA: a história política do futebol nos Jogos Olímpicos".

Disposto a entender o futebol em todas as suas peculiaridades, foi, a partir de 2000, já no segundo ano do curso de Educação Física e ainda descobrindo as possibilidades da área, que Sérgio Giglio encontrou o caminho que desejava. Ao cursar a disciplina "Aspectos Antropológicos da Motricidade Humana", encontra novas possibilidades de trabalhar com o futebol no ambiente acadêmico graças aos autores de Antropologia e esse olhar interdisciplinar.

Escreveu e participou da organização de livros voltados ao Futebol e Jogos

Olímpicos, incluindo "A História Política do Futebol Olímpico" (2018), "O Brasil e as Copas do Mundo: Futebol, História e Política" (2014) e "Múltiplos olhares sobre os Jogos Olímpicos" (2018). Além disso, possui capítulos em diversas obras sobre os temas e publicações em periódicos de diversas áreas de conhecimento.

Atualmente, Sérgio Settani Giglio é professor de graduação e pós-graduação em Educação Física da UNICAMP e coordenador do Grupo de Estudos e Pesquisas em Esporte e Humanidades (GEPEH) na mesma instituição de ensino. Ainda integra o MARGEM: Laboratório de Pesquisa e Educação Física e Humanidades da UNICAMP e o LUDENS (Núcleo Interdisciplinar de Estudos sobre Futebol e Modalidades Lúdicas), da USP. Sua pesquisa envolve temas como Futebol, Copa do Mundo, Jogos Olímpicos, Esporte e Política e Ensino dos Esportes Coletivos. Também é um dos editores do 


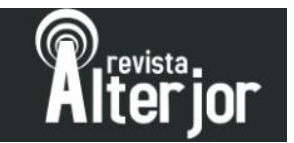

Ludopédio $^{2}$, portal de conteúdo que apresenta o futebol com um olhar interdisciplinar de diversas áreas de conhecimento das Ciências Humanas.

\section{Entrevista}

Gustavo de Araujo Longo: Primeiro, gostaria de perguntar como enxerga os Jogos Abertos do Interior no cenário esportivo nacional. Estamos falando de um evento que tem mais de 80 anos e que é considerado amador, apesar de reunir alguns dos principais atletas do país. Quais as relações que possui do ponto de vista comunicacional e de outros elementos, como econômico?

Sérgio Settani Gigio: A leitura que faço é à distância dos Jogos Abertos, especialmente porque é um evento quase invisível dentro da estrutura esportiva brasileira. Neste caso tem um ponto que, para mim, é crucial ao mesmo tempo em que é invisível, é extremamente importante. Isso gera um certo paradoxo dentro dessa estrutura do esporte. É invisível, na minha opinião, dentro do espaço que é dado pelas mais diferentes mídias na cobertura do evento, mas ele é muito importante no calendário esportivo de grande parte dos atletas brasileiros. Talvez a presença deste evento pela falta de visibilidade ou, melhor dizendo, pela forma como cada cidade se programa, em muitos casos para ganhar o maior número de medalhas e sem desenvolver de fato uma política esportiva para o município, acaba, para mim, perdendo o valor que poderia ter tanto no aspecto informativo quanto no intercâmbio esportivo entre as regiões. Acaba, muitas vezes, tendo um uso político, no sentido de investimento para ter mais visibilidade e destaque, mas nem sempre representa uma política pública efetiva de inserção do esporte dentro daquela cidade.

\footnotetext{
2 O Ludopédio nasceu em 2009 com a proposta de abordar o futebol a partir de uma análise interdisciplinar e reúne reportagens, artigos, dissertações, teses e demais obras técnicas e/ou artísticas sobre o tema. Disponível em: <https://www.ludopedio.com.br/> Acesso: 8. jun. 2020.
} 


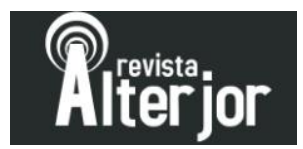

Gustavo de Araujo Longo: Do seu ponto de vista, é isto que explica essa invisibilidade? Em 2019, por exemplo, o evento reuniu Arthur Zanetti, campeão olímpico na ginástica, Daniele Hypólito, medalhista mundial também na ginástica, e Luiz Oliveira, neto de Servílio Oliveira, primeiro medalhista olímpico do país no boxe e ele próprio medalhista no Mundial Júnior da modalidade. O que explica essa invisibilidade mesmo com grandes nomes que, em tese, chamariam a atenção midiática?

Sérgio Settani Giglio: Olhando mais para a cobertura televisiva, deveria ter um grande interesse de mostrar esse circuito esportivo e não o faz. E não faz em detrimento de uma programação que pauta o esporte internacional, principalmente o futebol com as ligas europeias, e jogos como a NBA, por exemplo. Vão concorrer de maneira desleal com uma lógica de corrida pela audiência. Por mais que exista alguns atletas de grande visibilidade, a maioria presente nos Jogos Abertos do Interior não tem esse status que o Arthur Zanetti e a Daniele Hypólito possuem dentro do cenário brasileiro. Mas isso não deveria tirar o valor dessa competição e o espaço dentro da estrutura do jornalismo esportivo como um todo porque não é só invisível para a televisão; a mídia impressa também aborda pouco isso. Usando um jargão comum no meio, a justificativa é que "não atrai a atenção e não consigo vender publicidade quando falar dele, não consigo fazer nada". O contrapeso disso é que você deixa de fazer um jornalismo efetivo para mostrar as raízes do esporte, como a presença de um evento deste tipo gera um impacto enorme na cidade que organiza. Então, é muito mais por pautas e por opinião do editor de que não vai dar Ibope, então nem realiza a cobertura. É claro que essa é uma leitura de quem não é jornalista sobre esta ausência dos Jogos Abertos na cobertura midiática.

Gustavo de Araujo Longo: Como pesquisador, ainda acredita que os Jogos Abertos do Interior, do ponto de vista comunicacional, podem ser uma menor escala dos Jogos Olímpicos? A cobertura do evento regional poderia ser a mesma dos Jogos Olímpicos? 


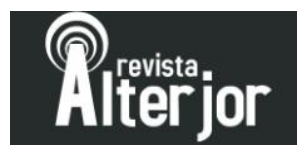

Sérgio Settani Giglio: Acredito que sim. Do ponto de vista do fazer jornalístico, de produzir pautas, histórias e materiais, deveria compor esse lugar de destaque. A gente, muitas vezes, diz que o Brasil é só o país do futebol, mas esta expressão também é validade quando a própria mídia não olha para outras modalidades. Dá impressão para a grande massa da população brasileira que, de fato, só existe futebol porque você encontra de maneira mais fácil na estrutura jornalística. Acho que os Jogos Abertos seriam um bom local para produzir matérias interessantes.

Mas fazendo um contraponto a esta ideia, me parece que os Jogos Abertos estaria no meio-termo disso, mais próximo da lógica dos Jogos Pan-americanos. Em experiências recentes nas últimas décadas, me parece que o brasileiro só se interessa pelo Pan, ou se interessou pelo evento, quando passou por aqui. Quando ele está em outro país, o interesse e a cobertura jornalística também diminuem. Qual é o segredo disso? O público não se interessa porque a mídia não mostra ou não mostra porque o público não se interessa? Tem uma equação aí que precisa ser enfrentada de alguma maneira. Boa parte da mídia parece que diz que o público não se interessa e, por isso, não cobre. Concorre com astros internacionais que estarão passando no mesmo horário e então é melhor nem comentar sobre isso. Ou se o pessoal só quer saber na mídia impressa de futebol, por que falar de outras coisas?

Gustavo de Araujo Longo: Mas tanto os Jogos Pan-americanos quanto os Jogos Abertos do Interior bebem da fonte dos Jogos Olímpicos com o conceito de invenção de tradições, de Eric Hobsbawn. Nesta visão, copia-se tradições, como os Jogos Abertos que também possuem sua chama olímpica acesa em Monte Alto. Não seria uma tentativa de vincular a "marca" aos Jogos Olímpicos justamente para atrair mais público?

Sérgio Settani Giglio: A leitura que faço é muito mais de vincular um diálogo com símbolos que a grande massa da população já conhece, como o quadro de medalhas, a pira olímpica, a tocha, elementos que compõem esse imaginário que chamam a atenção 


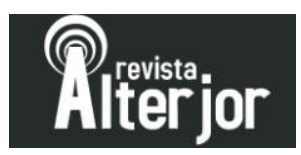

por ser um evento extraordinário, que acontece de quatro em quatro anos. Parece-me que é um diálogo com esses símbolos do que uma tentativa de falar "o que estamos fazendo aqui é a mesma coisa dos Jogos Olímpicos". Por que digo isso? Porque os Jogos Olímpicos têm essa dimensão mais universal por conta da participação de um maior número de atletas. Não digo do número efetivo de atletas, mas em termos de nacionalidades, eles vêm de diversos lugares e se constituiu ao longo do tempo em um grande evento. Os Jogos Abertos têm uma configuração que seria um pouco mais ordinária nesse ponto de vista. Ele acontece com uma frequência menor do que os Jogos Olímpicos, certo?

Gustavo de Araujo Longo: Sim, ocorrem anualmente. Mas falando dos Jogos Olímpicos, como o trabalho jornalístico realizado no Brasil na cobertura deste evento?

Sérgio Settani Giglio: Para pensar essa pergunta, é preciso dividir alguns lugares. Uma cobertura um pouco mais ampliada em minha leitura, e estou pensando mais a mídia impressa, que foi feita para os Jogos do Rio em 2016, alguns jornais aqui de São Paulo perderam isso. Apenas o Estadão (Jornal O Estado de S. Paulo) me parece que ainda mantém uma tentativa de dialogar com outras modalidades, mas de um modo ainda bem acanhado - embora tenha jornalistas que façam coberturas específicas de outras modalidades que não apenas o futebol. Durante os Jogos de 2016, houve uma tentativa de não falar só de futebol, tentar mostrar o que tem por aqui de outras modalidades. Mas passado esse evento, e estamos mais pertos dos Jogos de Tóquio do que estivemos do Rio, não visualizo uma grande cobertura na mídia impressa neste ponto de vista democrático, de falar de todas as modalidades. Esses meios vão, na minha leitura, fazer uma previsão, e como qualquer previsão é um risco, de cobrir as modalidades que os brasileiros têm uma chance maior de conquistar medalha e cobrir essas histórias. Já a TV talvez tente surfar um pouco nessa lógica da diversidade das modalidades mais inusitadas, mais distantes da nossa realidade. Até porque esses canais por assinatura às vezes abrem canais extras durante grandes eventos para tentar engajar mais a audiência, 


\section{Arejior}

mas fica atrelada à venda de patrocínio. Assim, não faria uma leitura de que estão simplesmente fazendo isso porque querem difundir essas modalidades. A partir da hora que abrem novas grades e novos programas, eles abrem novas estruturas para propagandas passarem naquele horário. Então, tem um quê comercial por trás dessa estrutura, tanto quanto o COI também funciona nessa lógica.

Gustavo de Araujo Longo: Neste caso, como acredita que deveria ser essa cobertura? Quais pautas deveriam ser abordadas em um evento poliesportivo e não são?

Sérgio Settani Giglio: Na minha opinião, há muitas pautas que poderiam ser feitas - são assuntos que gosto, mas que não têm que ser assim. De um modo geral, são as boas histórias que contam a trajetória desses atletas, o porquê deles pararem naquelas modalidades. No caso dos brasileiros, muitas vezes é uma ação quase individual de alguém que gostava de alguma modalidade e que cria um grupo e, desse grupo, sai esses atletas. É tentar entender um pouco da história por trás desses eventos, como se fosse olhar o que está no entorno e não só para dentro dos Jogos. A cobertura sobre os Jogos Olímpicos é extremamente importante e é igualmente importante falar sobre os resultados. Mas o que produz essas conquistas? Como é a rotina de treinamentos? Como é a estrutura esportiva? São pautas que deveriam aparecer. $\mathrm{Na}$ televisão, tinha um programa que cumpria bem isso na ESPN, o "Histórias do Esporte", que contava as histórias que não estão no mainstream, que não estavam colocadas ou que não tivessem sido contadas. É preciso render um pouco mais atrás dessas histórias: saber quem foi seu treinador ou treinadora no início, a realidade da sua cidade, enfim, contar um pouco das trajetórias. Para ser um atleta, precisa de um processo de preparação enorme, uma estrutura, estar nos grandes centros que promovem os grandes atletas - muitas vezes, essa pessoa vai ser captada de outros lugares. Isso é pouco contado. Quais são os sacrifícios que a pessoa faz para ser um atleta? Essas histórias, para mim, tem um potencial muito grande e precisam ser contadas. 


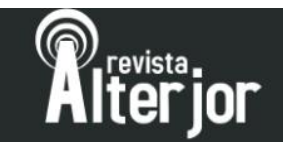

\section{REFERÊNCIAS}

GIGLIO, Sérgio Settani. Currículo do Sistema Lattes. Disponível em: <http://lattes.cnpq.br/9913693447254815 > Acesso em 31 mai. 2020.

. Entrevista concedida a Gustavo de Araújo Longo, com pauta e edição de Luciano Victor Barros Maluly e Gustavo de Araújo Longo. Áudio. 1 arquivo .mp3 (37m03s). 5. mar. 2020.

LABORATÓRIO DE ESTUDOS EM MÍDIA E ESPORTE. Sergio Settani Giglio Entrevista Completa. 2019. (31m40s). Disponível em: <https://youtu.be/oV1D4wkhCW0> Acesso em: 31 mai. 2020.

UNIVESP. Fala Doutor: Sergio Settani Giglio - COI x FIFA, a história política do futebol - PGM 110. 2014 (30m40s). Disponível em: 〈https://youtu.be/k14w-Zy6cqg> Acesso em: 31 mai. 2020. 